\title{
ANÁLISE COMPARATIVA DAS PERCEPÇÕES DE PROFISSIONAIS DE SAÚDE E PUÉRPERAS ACERCA DO PARTO HUMANIZADO: REVISÃO INTEGRATIVA DE LITERATURA
}

\author{
Larissa Sousa de Freitas', Leonardo Pereira Bastos ${ }^{2}$, Mariane Costa Santos de Tavares ${ }^{3,}$, Iasmin \\ Alves Cruz Moy Santana ${ }^{4}$, Erica Medeiros de Alencar ${ }^{5}$, Raiza Fraga Rosa Motta ${ }^{5}$, Evaldo Araújo \\ Fontes Filho ${ }^{5}$, Layssa Ravelle Gomes Silva Andrade ${ }^{5}$, Kelle Silva Castro ${ }^{5}$ and Geovana Santos Sá 6
}

${ }^{1}$ Autora correspondente. Curso de Graduação em Medicina. Faculdades Santo Agostinho de Vitória da Conquista

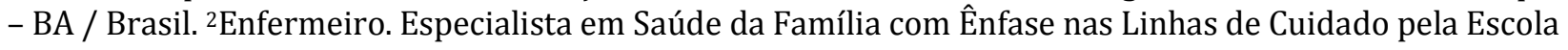
Estadual de Saúde Pública - EESP/SESAB. Docente do Curso de Graduação em Medicina. Faculdades Santo Agostinho de Vitória da Conquista - BA / Brasil. ${ }^{3}$ Fisioterapeuta. Especialista em Fisioterapia Respiratória e Terapia Intensiva pelas Faculdades Integradas Pitágoras, Pós -Graduada em Deficiências Múltiplas e Sensoriais. Curso de Graduação em Medicina Faculdades Santo Agostinho, Vitória da Conquista - BA / Brasil. 4,5,6 Curso de Graduação em Medicina. Faculdades Santo Agostinho de Vitória da Conquista - BA / Brasil.

\section{ARTICLE INFO}

Article History:

Received $25^{\text {th }}$ January, 2021

Received in revised form

$17^{\text {th }}$ January, 2021

Accepted $19^{\mathrm{h}}$ February, 2021

Published online $30^{\text {th }}$ March, 2021

Key Words:

Parto Humanizado. Saúde da Mulher. Saúde Sexual e Reprodutiva.

*Corresponding author:

Mariane Costa Santos de Tavares

\begin{abstract}
O período gestacional e $\mathrm{O}$ período gestacional e trabalho de parto são momentos descritos como peculiares na vida reprodutiva da mulher, com repercussões biopsicossociais. Um trabalho de parto com assistência humanizada permite que a mulher consiga viver em plenitude os sentimentos maternos com a chegada de uma nova vida. Sabendo da relevância da humanização do trabalho de parto, o objetivo deste estudo foi analisar comparativamente as percepções de puérperas e profissionais de saúde acerca do parto humanizado. Trata-se de uma revisão integrativa de literatura, cuja busca por estudos se deu nas bases de dados vinculadas à Biblioteca Virtual em Saúde (BVS), Scientific Electronic Libray Online (SciELO), Literatura LatinoAmericana e do Caribe/Índice Bibliográfico Español em Ciencias de la Salud (Lilacs/Ibecs), e Medical Literature Analysis and Retrievel System Online (Medline). Utilizou-se os descritores em ciências da saúde: Parto humanizado, Saúde da mulher, Saúde sexual e reprodutiva. Após análise dos estudos encontrados emergiram três categorias temáticas: Definição de parto humanizado, Violência obstétrica na percepção de puérperas, Violência obstétrica segundo visão dos profissionais. A necessidade de melhor abordagem do parto humanizado é referida tanto por profissionais como puérperas. A violência obstétrica, embora admitida por alguns profissionais tende a ser mais percebida pelas puérperas, e possui grande carga psíquica desencadeando traumas e transtornos emocionais.
\end{abstract}

Copyright (C) 2021, Larissa Sousa de Freitas et al. This is an open access article distributed under the Creative Commons Attribution License, which permits unrestricted use, distribution, and reproduction in any medium, provided the original work is properly cited.

Citation: Larissa Sousa de Freitas, Leonardo Pereira Bastos, Mariane Costa Santos de Tavares et al. "Análise comparativa das percepções de profissionais de saúde e puérperas acerca do parto humanizado: revisão integrativa de literatura”, International Journal of Development Research, 11, (03), 45667-45670.

\section{INTRODUÇÃO}

A prática de interrupção gestacional pode ser realizada via vaginal ou via cirurgia cesárea. A cesariana é considerada um procedimento que é capaz de atender a diferentes necessidades é é amplamente sangramentos, gritos, dor, secreção vaginal e é compreendida ainda como uma prática mais humanizada e socializável (NAKANO; BONAN; TEIXEIRA , 2017). Nesta perspectiva, quando há indicações clínicas adequadas e baseadas em fundamentos científicos, a cesárea se torna uma importante intervenção no sentido de reduzir as taxas de morbimortalidade. Apesar disto, esta prática é fortemente 
pré-natal, poder aquisitivo e setor de realização que pode ser público ou privado (MADEIRO; RUFINO; SANTOS, 2017). Já o parto natural, realizado por via vaginal, é um procedimento que permite o nascimento sem intervenções cirúrgicas ou relacionadas a outros procedimentos dispensáveis. Entre os benefícios do parto natural, está principalmente a segurança para a parturiente, a menor incidência de complicações como infecções e hemorragias e a recuperação rápida. Além disto, o parto natural promove uma maior quantidade de nascimentos a termo e reduz alterações respiratórias no recémnascido e promove um aleitamento materno precoce (COSTA et al., 2015). Diante disto, a escolha pelo tipo de parto deve ser uma decisão conjunta entre a equipe de saúde e a mulher, levando-se em consideração todos os fatores que influenciam e que possam assegurar o bem estar materno-fetal. É essencial que os profissionais da saúde forneçam conhecimento necessário e suporte para que a melhor escolha seja feita, de modo a viabilizar a autonomia e o empoderamento feminino (MADEIRO; RUFINO; SANTOS, 2017).

Atualmente o Brasil é considerado o país com o maior número de cesáreas no mundo. Desde o ano de 2009 o procedimento por parto cesáreo superou o número total de nascimentos por parto vaginal, sendo que, a Organização Mundial da Saúde recomenda que $15 \%$ do total de partos deve ser realizado via cesariana, prevalecendo assim, partos via vaginal. Apesar disto, não é o que acontece na realidade brasileira, visto que, no ano de 2012 cerca de $45 \%$ do total de partos realizados pelo Sistema Único de Saúde (SUS) foi realizado via cesárea, enquanto no setor privado, este percentual atingiu $85 \%$ (BOREM et al., 2015).

Nesta perspectiva, o parto cesáreo é uma prática que aumentam os riscos de morbidade e mortalidade em dez vezes quando comparado ao parto normal. Entre os principais riscos que envolvem o parto via cesárea estão a embolia pulmonar, complicações relacionadas com anestesia, infecções puerperais, hemorragias e o óbito. O recémnascido também corre sérios riscos com esta prática, como a prematuridade iatrogênica, anóxia, problemas relacionados com o aparelho respiratório, icterícia fisiológica e aumenta substancialmente a prevalência de hospitalizações em Unidades de Terapia Intensiva Neonatal (PINTO et al., 2019). Bittar (2018) afirma que as indicações eletivas de parto cesáreo quando realizados no período entre 37 e 38 semanas e seis dias pode ocasionar sérias repercussões. Esta interrupção pode ocorrer devido a complicações fetais, complicações maternas ou outras etiologias definidas, o que corresponde a cerca de $25 \%$ dos partos. Apesar disto, a grande maioria dos recém nascidos termo precoce são devido a intervenções médicas desnecessárias podendo desencadear estresse fetal, materno e também processos inflamatórios (PINTO et al., 2018). Diante disto, percebe-se que a atenção oferecida a mulher durante o período de pré-natal, parto e puerpério é de fundamental importância para a melhoria da qualidade de vida e da redução da morbidade e mortalidade. Assim, a violência obstétrica, a ausência do parto humanizado e a morte materna são fatores que violam os direitos das mulheres e refletem a qualidade do serviço oferecido no sistema de saúde (RODRIGUES; CAVALCANTE; VIANA, 2019).

Villamil, Botero e Guzmán (2020) afirmam que o momento do parto é decisivo para muitas mulheres. Durante todo o período gestacional a mulher passa por alterações hormonais, corporais e emocionais, abrigando em seu interior um novo ser. O parto representa assim, a primeira separação da mulher, com seu filho. Logo, diz respeito ao nascimento do neonato, que pode ocorrer por via natural, correspondendo a expulsão do feto através da via vaginal, ou por cesariana, sendo realizado por meio de intervenção cirúrgica para extrair o feto do útero materno (ZUGAIB, 2016). Portanto, antigamente, era visto apenas como sinônimo de fazer partos, porém, com o passar do tempo e com os avanços tecnológicos e educacionais é nítido a necessidade do ciclo gravídico puerperal ser valorizado e acompanhado durante todo o seu processo, inclusive, antes da concepção. A Política Nacional de Humanização (PNH) define a humanização como a inclusão das pessoas nos espaços de atenção, gestão e formação em saúde, de modo que não seja apenas um movimento institucional, mas também ético e afetivo. Desta maneira, é imprescindível a participação dos sujeitos, não apenas de forma individual, mas coletiva, para que haja o compartilhamento de ideias, desejos e conhecimento. Perante o exposto, é notório a carência desse tipo de atendimento durante o período gestacional e no ato do parto, tendo em vista o número crescente de partos cesarianas sem precisão, muitas vezes até sendo realizado de forma contraria ao desejo da gestante, devido a maior comodidade para os profissionais de saúde, excluindo o desejo materno. Posto isso, o atendimento realizado de forma humanizada e segura acarreta maior tranquilidade e realização no momento do parto, diminuindo dessa forma o número de partos executados com intervenção cirúrgica sem necessidade (BRASIL, 2014). Em tal contexto, o objetivo deste estudo foi analisar comparativamente as percepções de puérperas e profissionais de saúde acerca do parto humanizado.

\section{MATERIAIS E MÉTODOS}

A pesquisa caracteriza-se como revisão integrativa de literatura, que permite uma maior familiaridade com o tema abordado. Tal metodologia baseia-se em uma busca qualificada na literatura científica, a partir de fontes secundárias, que garante maior aprofundamento nos conhecimentos temáticos, mas também uma revisão crítica dos dados encontrados. Conforme Souza, Silva e Carvalho (2010, p.102) tal método de pesquisa "proporciona a síntese de conhecimento e a incorporação da aplicabilidade de resultados de estudos significativos na prática”. A busca por estudos se deu nas bases de dados vinculadas à Biblioteca Virtual em Saúde (BVS), Scientific Electronic Libray Online (SciELO), Literatura LatinoAmericana e do Caribe/Índice Bibliográfico Español em Ciencias de la Salud (Lilacs/Ibecs), e Medical Literature Analysis and Retrievel System Online (Medline). Utilizou-se os descritores em ciências da saúde: Parto humanizado, Saúde da mulher, Saúde sexual e reprodutiva. Como critérios de inclusão foram considerados artigos científicos originais, que abordassem o tema pesquisado e permitissem acesso integral ao conteúdo do estudo. Tal busca foi realizada no período compreendido entre janeiro de 2021 e março do mesmo ano.

\section{RESULTADOS E DISCUSSÃO}

Após análise dos estudos encontrados emergiram três categorias temáticas: Definição de parto humanizado, Violência obstétrica na percepção de puérperas, Violência obstétrica segundo visão dos profissionais.

Definição de parto humanizado: Por volta do século XX o processo de medicalização dos nascimentos ampliou a quantidade de estabelecimentos para partos, como clínicas médicas e maternidades. Neste contexto, os partos domiciliares foram paulatinamente substituídos por partos hospitalares, assistidos anteriormente por parteiras, neste momento passaram a ser assistidos por médicos obstetras que utilizavam intervenções e práticas de padronização e ordenamento à medicina praticada em ambiente hospitalar (SILVA et al., 2019). Apesar da recomendação do Ministério da Saúde relacionado a prevalência de partos vaginais, esta prática associa-se com a violência obstétrica. Um estudo realizado em uma maternidade na região do Nordeste demonstrou que $86,57 \%$ das mulheres que deram a luz via parto vaginal foram vítimas de violência obstétrica, sendo que $39 \%$ permaneceu em posição supina, $65 \%$ esforço de empurrar e $41 \%$ administração de ocitocina. Um outro estudo realizado na maternidade de São Paulo corrobora com estas informações ao afirmar que em $27,3 \%$ das mulheres foram realizados procedimentos sem consentimento da mesma, como episiotomia, enema e amniotomia artificial (CARVALHO; BRITO, 2017). Nesta perspectiva, a atenção ao parto humanizado é classificada em quatro categorias para que possa orientar a prática e a conduta profissional, baseados na utilidade, risco e eficácia. As categorias são as que com uma alta frequência são utilizadas de forma inapropriada, as que são ineficazes e que devem ser evitadas, as que possuem pouca evidência 
científica e que devem ser utilizadas com cautela e as que são comprovadamente úteis e que devem ser estimuladas (CARVALHO; GÖTTEMS; PIRES, 2015). Baseado nestas evidências, o modelo de assistência obstétrica institucionalizado passou a ser questionado, assim como as práticas de interrupção e de intervenção desnecessárias. E desta forma, a qualidade ao serviço prestado as mulheres e aos recém nascidos passou fazer parte de políticas e estratégias de humanização, de modo a permitir a participação das mulheres no processo e a sua autonomia (SILVA; NASCIMENTO; COELHO, 2015).

Insistir em intervenções sem comprovação científica de eficácia e que são desnecessários impactam diretamente nas taxas de mortalidade. Estima-se que no ano de 2013 houve 210 óbitos maternos para cada 100.000 nascidos vivos, representando um total de 289.000 mulheres que foram a óbito devido a complicações durante a gestação, parto e puerpério (CARVALHO; GÖTTEMS; PIRES, 2015). Por isto, como forma de humanizar, ampliar e qualificar a humanização ao parto, o Ministério da Saúde lançou a Política de Atenção Integral a Saúde da Mulher (PAISM) (CASSIANO et al., 2015). Esta política é uma estratégia para oferecer atenção integral a mulheres em período de pré-natal, parto, puerpério, urgências obstétricas e aborto. Além disto, é responsável ainda pela vigilância epidemiológica do óbito materno e violência sexual e doméstica. Além disto, abrange políticas de prevenção, planejamento reprodutivo e saúde mental (FERNANDES et al., 2015). Como forma de humanizar ainda mais este momento para as gestantes, em 2005 foi aprovada a Lei Federal n. 11.108 que obriga as redes públicas e conveniadas a permitirem a presença de um acompanhante durante todo o processo de trabalho de parto, parto e após o parto (BRASIL, 2011). A Lei do Acompanhante promoveu maior satisfação das parturientes, que relatam tranquilidade, conforto e maior vínculo entre pais e recém-nascido (SOUZA; GUALDA, 2016).

Diante disto, as reflexões acerca da humanização do parto têm sido bastante difundidas no campo da saúde como um direito de todos os cidadãos. As políticas e as estratégias de saúde têm o dever de oferecer um parto humanizado de modo a respeitar a autonomia da mulher e a dignidade humana (BRANDT et al., 2018). Sendo assim, humanização vai além da definição de fazer saúde, pois abarca questões estruturais envolvidos na lógica social, funcional e física, por isto, é essencial que as questões sociais e culturais sejam levadas em consideração (CASSIANO et al., 2015). Em estudo realizado por Rodrigues et al. (2017) os pesquisadores ressaltam os ganhos na humanização do parto com a implantação da Rede Cegonha. O atendimento humanizado, acolhimento adequado, e suporte emocional proporcionado fez com que $89,4 \%$ da amostra relatassem segurança no momento do parto. O estudo, envolvendo 3.765 puérperas de parto transpelviano aponta ainda a importância de orientações claras, respeito à mulher, e estímulo ao seu protagonismo no processo do parto para uma adequada humanização deste.

Violência Obstétrica na percepção de puérperas: A violência contra a mulher é multifacetada, sendo que a violência obstétrica é descrita pela literatura como uma "ação invasiva ao corpo da mulher" casando danos físicos, psicológicos ou ambos (ESTUMANO et al., 2017). A própria falha na humanização do cuidado à gestante e puérpera é referida como uma violência. A negligência ao acolhimento, desinformação, desrespeito aos direitos estabelecidos por lei são algumas das situações mais comuns de violência obstétrica (SILVA; SILVA; ARAÚJO, 2017, p.26). Em estudo realizado por Rocha e Grisi (2017) os autores ressaltam que a violência obstétrica é extremamente traumática repercutindo negativamente na saúde sexual e reprodutiva de mulheres violentadas. Muitas vezes a gestante sequer conhece seus direitos, e somente após o parto e relato das situações vivenciadas consegue perceber ou identificar a situação de violência a que foi exposta. Muitas mulheres concebem a falta de humanização como algo comum e rotineiro, como se fizessem obrigatoriamente parte do ritual do parto. Diversas são as definições trazidas por mulheres sobre a violência obstétrica, desde agressões verbais, maus tratos físicos, ausência de analgesia no parto, atitudes que transcendem o significado de humanização deficiente passando a constituir relatos de violência sofrida e/ou percebida. A realização de episiotomia sem consentimento, uso de força física da equipe de saúde para "auxiliar" a expulsão do bebê, a demora no trabalho de parto, ou ainda a proibição de acompanhante foram também referidas como situações de violência por mulheres entrevistadas (SILVA; SILVA; ARAÚJO, 2017). Há ainda relatos de realização de toque constante e agressivo, descaso, procedimentos realizados sem permissão ou explicação prévia às parturientes, além de manobras como a manobra de Kristeller (NASCIMENTO et al., 2017). Tal manobra embora não seja recomendada pela Organização Mundial da Saúde (OMS) ainda é realizada por muitas equipes de saúde, consistindo em aplicação de pressão na parte superior do útero. A técnica é referida como obsoleta, e pode causar desde lesão do esfíncter anal, até ruptura uterina (ROCHA; GRISI, 2017; PALMA; DONELLI, 2017). São raros os casos de mulheres que no momento do trabalho de parto exijam seus direitos(AGUIAR; RODRIGUES, 2017). O medo e a submissão à equipe profissional também faz com que mesmo mulheres que identificam a situação de violência no momento da ocorrência se calem, visto que estão em situação de vulnerabilidade(ROCHA; GRISI, 2017). Dentre as consequências da violência obstétrica e/ou da falta de humanização do parto a literatura cita quadros de depressão, ansiedade, medo de gestações futuras, além de disfunções sexuais, que impactam diretamente a saúde mental e qualidade de vida das mulheres que sofreram violência (SOUZA; RATTNER; GUBERT, 2017).

Violência obstétrica segundo visão dos profissionais: Durante o trabalho de parto a mulher está imersa em um evento extremo, visceral e primitivo, que interfere significativamente em sua forma de atuar. Em contextos extremos as convenções sociais muitas vezes são ignoradas pela urgência do ato primitivo evocado. Em tal contexto, a situação de violência geralmente ocorre quando o médico ou equipe assistencial ignora tal peculiaridade exige da mulher uma postura de submissão, e até mesmo, comportamento moldado socialmente. $\mathrm{O}$ ato de questionar sobre manobras, uso de ocitocina, episiotomia e cesárea é referido por médicos como "posturas inadequadas", sendo que alguns referem que "contrariar as práticas médicas" são incorretas, e inaceitáveis, sendo tal conduta influenciada pela mídia. A aquisição de conhecimentos e luta da mulher por respeito e direitos reprodutivos é ainda passível de discriminação e precursora da violência obstétrica (SENS; STAMM, 2019).

Em estudo descritivo realizado por Cardoso et al. (2017) os pesquisadores buscaram avaliar a percepção dos profissionais de saúde sobre violência obstétrica. De acordo com o estudo a maior parte dos profissionais se mostrou "desconhecedora do tema violência obstétrica". Contudo, $40 \%$ destes referram ter tido contato com o tema, embora apenas $15 \%$ tenha admitido ter cometido o ato da violência obstétrica. Um ponto levantado pelos entrevistados que afirmaram já ter cometido atos de violência obstétrica é o descompasso entre as exigências dos serviços de saúde, rotinas exaustivas, e até mesmo a postura de determinadas gestantes / parturientes.

Alguns profissionais referiram ainda, que muitas vezes a ignorância ou arrogância do profissional pode o levar a cometer atos de violência obstétrica. Palharini (2017) pontua em seu estudo que embora a violência obstétrica já seja definida pela OMS como um problema de saúde pública, há uma verdadeira resistência da classe médica em enfrentar de fato o debate, propondo mudanças na assistência à parturiente. $\mathrm{O}$ discurso biomédico hegemônico é criticado pelo enfoque patológico que é dado na gestação e parto, com frequente eliminação do enfoque sociocultural. A perda do protagonismo pela mulher, em um ato essencialmente natural, o abuso de procedimentos artificiais, e consequentemente a violação dos direitos humanos, reprodutivos e sexuais das mulheres são alguns marcos reprováveis de tal modelo assistencial. Muitos médicos defendem que tais práticas hoje trariam menor risco na prática obstétrica, embora grande percentual dos partos cesáreos realizados no Brasil não possuam de fato embasamento científico para sua indicação. 


\section{CONSIDERAÇÕES FINAIS}

A ausência de humanização do parto, e até mesmo a ocorrência de violência obstétrica são relatados na literatura como uma realidade, percebida tanto por profissionais como por puérperas. O desconhecimento de seus direitos, a vulnerabilidade, e a situação em si comumente faz com que a mulher se cale frente ao sofrimento, ou ainda, perceba a situação como violenta apenas após a alta hospitalar. A literatura consultada ressalta que mesmo em mulheres com conhecimento sobre o conceito e práticas violentas a medicalização e prevalência do saber médico faz com que culturalmente tais mulheres "aceitem" os atos sofridos/percebidos como parte integrante do processo de trabalho de parto. A necessidade de melhor abordagem do parto humanizado é referida tanto por profissionais como puérperas. A violência obstétrica, embora admitida por alguns profissionais tende a ser mais percebida pelas puérperas, e possui grande carga psíquica desencadeando traumas e transtornos emocionais.

\section{REFERÊNCIAS}

AGUIAR, E. M; RODRIGUES, M. S. 2017. Violência obstétrica durante o processo de parturição: relato de mulheres de uma unidade de saúde do interior de Minas Gerais. Revista Brasileira de Ciências da Vida. v. 5, n. 2, p. 1-29, jul.

BOREM, Paulo et al. 2015. Aumento do percentual de partos vaginais no sistema privado de saúde por meio do redesenho do modelo de cuidado. Rev Bras Ginecol Obstet, São Paulo, v. 37, n. 10, p. 446-454.

BRANDT, Gabriela Pinheiro et al. 2018. Violência obstétrica: a verdadeira dor do parto. Rev. Gestão \& Saúde, v.19, n.1, p.19-37.

BRASIL. Ministério da Saúde. Portaria n.1.459, de 24 de junho de 2011. Institui, no âmbito do Sistema Único de Saúde - SUS - a Rede Cegonha. Diário Oficial da União, Brasília, DF, 2011.

CARDOSO, Ferdinand José da Costa et al. Violência obstétrica institucional no parto: percepção de profissionais da saúde. Rev enferm UFPE, v.11, n.9, p. 3346-3353, 2017.

CARVALHO, Elisabete Mesquita Peres; GÖTTEMS, Leila Bernarda Donato; PIRES, Maria Raquel Gomes Maia. Adesão às boas práticas na atenção ao parto normal: construção e validação de instrumento. Rev Esc Enferm USP, São Paulo, v. 49, n. 6, p. 890898, 2015.

CARVALHO, Isaiane da Silva; BRITO, Rosineide Santana. Formas de violência obstétrica vivenciadas por mães que tiveram parto normal. Doente. glob., São Paulo, v. 16, n. 47, p. 71-97, 2017.

CASSIANO, Alexandra do Nascimento et al. Percepção de enfermeiros sobre a humanização na assistência de enfermagem no puerpério imediato. J. res.: fundam. care. online, São Paulo, v. 7, n. 1, p. 2051-2060, 2015.

COSTA, Maiara Naves et al. Parto: direito de escolha da mulher. Saber Digital, Rio de Janeiro, v. 8, n. 1, p. 146-163, 2015.

ESTUMANO, V. K. C. et al. Violência obstétrica no Brasil: casos cada vez mais frequentes. Revista Recien. São Paulo, v. 7, n. 19, p. 83-91, 2017.

FERNANDES, Leiliane Teixeira Bento et al. Atuação do Enfermeiro no Gerenciamento do Programa de Assistência Integral à Saúde da Mulher. Revista Brasileira de Ciências da Saúde, São Paulo, v. 20, n. 3, p. 219-226, 2015.

FERREIRA, Haroldo da Silva. Redação de trabalhos acadêmicos nas áreas das ciências biológicas e da saúde. Rio de Janeiro: Editora Rubio, 2011.

GIL, Antônio Carlos. Como elaborar projetos de pesquisa. 5. ed. São Paulo: Atlas, 2010.
MADEIRO, Alberto; RUFINO, Andréa Cronemberger; SANTOS , Aline Oliveira. Partos cesáreos no Piauí: tendência e fatores associados no período 2000-2011. Epidemiol. Serv Saude, Brasilia, v. 26, n. 1, p. 81-90, 2017.

NASCIMENTO, Laís Chaves do et al. Relato de puérperas acerca da violência obstétrica nos serviços públicos. Rev. enferm. UFPE, v.11, n.5, p. 2014-2023, 2017.

PALHARINI, Luciana Aparecida. Autonomia para quem? O discurso médico hegemônico sobre a violencia obstétrica no Brasil. Cad. Pagu, Campinas, n. 49, e174907, 2017.

PALMA, C. F.; DONELLI, T. M. S. Violência obstétrica em mulheres brasileiras. Psico, Porto Alegre, v. 48, n. 3, p. 216-230, 2017.

PINTO, Jessika Nauama Silva et al. Incidência de parto cesárea em uma maternidade no município de Porto Velho -RO em 2017. Revista Eletrônica Acervo Saúde, [S. l.], v. 33, p. 1-6, 2019.

ROCHA, Mágda Jardim; GRISI, Érika Porto. Violência obstétrica e suas influências na vida de mulheres que vivenciaram essa realidade. Id on Line Rev. Mult. Psic. v.11, n. 38. 2017.

RODRIGUES , Antonia Regynara Moreira; CAVALCANTE , Ana Egliny Sabino; VIANA, Aleide Barbosa. Mortalidade materna no Brasil entre 2006-2017: análise temporal. Revista Tendências da Enfermagem Profissional , [S. l.], v. 11, n. 1, p. 3-9, 2019.

RODRIGUES, Francisca Alice Cunha et al. Violência obstétrica no processo de parturição em maternidades vinculadas à Rede Cegonha. Reprodução \& Climatério, v.32, n.2, p.78-84, 2017.

SENS, Maristela Muller; STAMM, Ana Maria Nunes de Faria. Percepção dos médicos sobre a violência obstétrica na sutil dimensão da relação humana e médico-paciente. Interface (Botucatu), Botucatu, v. 23, e180487, 2019

SILVA , Andréa Lorena Santos; NASCIMENTO, Enilda Rosendo; COELHO , Edméia de Almeida Cardoso. Práticas de enfermeiras para promoção da dignificação, participação e autonomia de mulheres no parto normal. Esc Anna Nery, [S. l.], v. 19, n. 3, p. 424-431, 2015.

SILVA, Fernanda et al. "Parto ideal": medicalização e construção de uma roteirização da assistência ao parto hospitalar no Brasil em meados do século XX. Saúde Soc, São Paulo, v. 28, n. 3, p. 171184, 2019.

SILVA, Francisca Martins; SILVA, Milécyo de Lima; ARAÚJO, Flávia Nunes Ferreira de. Sentimentos Causados pela Violência Obstétrica em Mulheres de Município do Nordeste brasileiro. Rev Pre Infec e Saúde, v.3, n.4, p.25-34, 2017.

SOUZA , Silvana Regina Rossi Kissula; GUALDA, Dulce Maria Rosa. A experiência da mulher e de seu acompanhante no parto em uma maternidade publica. Texto Contexto Enferm, [S. l.], v. 25 , n. 1 , p. 2051-2060, 2016

SOUZA, Karina Junqueira de; RATTNER, Daphne; GUBERT, Muriel Bauermann. Institutional violence and quality of service in obstetrics are associated with postpartum depression. Rev. Saúde Pública, São Paulo, v. 51, 69, 2017

SOUZA, Marcela Tavares de; SILVA, Michelly Dias da; CARVALHO, Rachel de. Revisão integrativa: o que é e como fazer. Einstein, v.8, n.1, p. 102-6, 2010.

VILLAMIL, M.M.L.; BOTERO,M.D.P.A.; GUZMÁN, C.I. Assistência humanizada à gravidez: o olhar de gestantes que frequentam uma unidade de saúde hospitalar. Enfermería Actual de Costa Rica, San José, n. 38, p. 180-195, jun. 2020.

ZUGAIB, Marcelo. Obstetrícia. $3^{\mathrm{a}}$ ed. Barueri, São Paulo: Manole, 2016. 